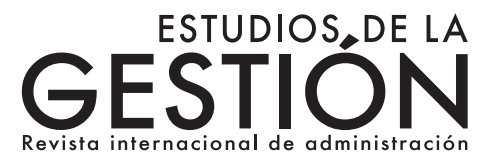

\title{
Barreras invisibles al comercio, las medidas no arancelarias y la capacidad exportadora de las empresas*
}

\author{
Entrevista a Cristian Ugarte ${ }^{* *}$
}

¿Cómo se define una medida no arancelaria (MNA) y cómo estas medidas se pueden convertir en un obstáculo para el comercio?

$\mathrm{Al}$ cubrir un amplio espectro de regulaciones, leyes y reglamentos, la manera más simple de definir las medidas no arancelarias (MNA) es por lo que no son, es decir, toda reglamentación o norma que se aplica al comercio y que no corresponde a ningún tipo de arancel aduanero. Esta definición engloba una gran cantidad de medidas sanitarias, fitosanitarias, pruebas, certificaciones, reglas de origen y procedimientos aduaneros, entre otros.

Las MNA están presentes en las operaciones diarias de cada exportador en todo el mundo; no existe una estadística del número de MNA que se aplican a cada producto, pero claramente la totalidad de los productos exportados está sujeta mínimamente al llenado de una declaración aduanera. Por lo tanto, todos los productos exportados está sujeta al menos a una MNA. Al ser varias reglamentaciones que se entrelazan y se concatenan para la exportación de un producto, un pequeño y mínimo disfuncionamiento puede generar retrasos, discrepancias, o simples pérdidas de eficiencia que tienen un impacto en la operación de exportador. Las posibilidades de que una MNA se convierta en un obstáculo al comercio son muchas.

\footnotetext{
* Entrevista realizada y sistematizada por Wilson Araque Jaramillo, economista y director del Área Académica de Gestión y de la revista Estudios de la Gestión de la Universidad Andina Simón Bolívar, Sede Ecuador.

** Analista de Mercados, Centro de Comercio Internacional (ITC).
} 
¿Cuáles son los propósitos principales que tienden a estar detrás de la presencia de una MNA?

Este es un punto importante. Hay que recalcar que la gran mayoría de las MNA son aplicadas por los países por razones legítimas de protección de la salud, del medioambiente, o incluso de la seguridad nacional. Las MNA tienen un objetivo regulatorio y no buscan incomodar necesariamente al comercio.

¿Cuál es el grado de impacto que puede tener una MNA en la capacidad de exportación empresarial de países como Ecuador?

Ecuador tiene una oferta exportadora que está muy ligada al sector agrícola y pesquero (bananos, flores, camarones, cacao, frutas, etc.) y todos estos productos tienen un tiempo de vida -o de venta- limitado. Cualquier retraso que pudiese surgir en estas cadenas de exportación podría generar retrasos y costos asociados que pueden generar pérdidas de producto, rechazo a destino, baja capacidad en la posibilidad de comercialización del producto, etc. No es cierto que las MNA no afecten a los productos manufacturados, pero la sensibilidad en cuanto al tiempo no es la misma que para un producto perecible.

¿Cómo deberían las empresas enfrentar las exigencias que están detrás de $M N A$ relacionadas a certificación de calidad, certificados sanitarios, certificados de origen y trámites aduaneros?

Pienso que existen dos fases cruciales para sobrellevar las exigencias fijadas por las MNA. La primera consiste en informarse acerca de las mismas, es una tarea complementaria a la inteligencia de mercado. Un exportador que busca oportunidades en otros países debe no solo identificar las oportunidades, sino también comprenderlas en plenitud. Por ejemplo, en este sentido, las Herramientas de análisis de mercados del Centro de Comercio Internacional (ITC) proveen información gratuita, pero también existen otros sitios web o incluso agencias nacionales que proveen este tipo de información, la cual debe ser buscada, de forma permanente, por los empresarios interesados en la aventura exportadora.

La segunda fase -que implica costos, tiempo y constancia- es la conformidad con esos reglamentos. Muchas veces las normas prevén procesos de 
certificación y verificación de la conformidad y creo que es importante que los exportadores se acoplen a este cuadro de trabajo. Las MNA tienen un carácter obligatorio en los países que se aplican; no cumplirlas implicaría, probablemente, un rechazo y, así, una oportunidad perdida, ya que otro exportador, de algún lugar del mundo, sí hará el esfuerzo y ganará ese mercado.

¿Cuál debería ser el enfoque y alcance de las políticas públicas que un gobierno debe definir para ayudar a las empresas a enfrentar los desafios que están detrás de las MNA?

El enfoque que se debe adoptar es la mejora continua de la implementación de las MNA, pues ni los exportadores ni tampoco las organizaciones internacionales que trabajan en estos temas buscan una eliminación total de las MNA, ya que un mundo sin reglas y normas no es viable en temas de comercio. Lo que sí es indispensable es el cuestionamiento con relación a temas como: ¿cumple la norma un objetivo legítimo para mantenerla?, ¿existe alguna manera de simplificarla para evitar documentación desmedida, innecesaria o irrelevante?, ¿existe una manera de obtener información ex ante para poder agilizar el trámite?, ¿puede habilitarse un canal de información que sea más ágil y claro en tiempo y costos del procedimiento?, en fin, ¿cómo se puede ganar eficiencia en la implementación de las MNA?; en definitiva, el objetivo es de siempre continuar mejorando el servicio público que se brinda a los ciudadanos y empresas.

Desde el ámbito del sector privado, ¿cuál debería ser el rol de los gremios a la hora de ayudar a las empresas a enfrentar los desafios que están detrás de las MNA?

Entre un 70 y $80 \%$ de las empresas en los países son pyme, incluso en los países en desarrollo este porcentaje es aún mayor. Lamentablemente, las pyme no tienen músculo financiero o un departamento de exportaciones que pueda llevar adelante toda la inteligencia de mercado necesaria para finalmente exportar con éxito su producto. Por lo tanto, los gremios tienen un rol importante en fomentar el emprendimiento exportador a través de la diseminación de las bondades y buenas prácticas de la inteligencia comercial. De otra parte, los gremios tienen también un rol importante a la hora de ser interlocutores privilegiados con el sector público y, así, estar siempre atentos 
para señalar cualquier dificultad o situación engorrosa que puede surgir en las operaciones comerciales de sus miembros, en particular de quienes son considerados como pyme.

En el caso de la academia, ¿qué rol podría cumplir en el momento de ayudar a las empresas a enfrentar los desafios que están detrás de las MNA?

La academia ha cumplido y seguirá cumpliendo un rol importante al mostrar que las MNA pueden tener una incidencia negativa en las exportaciones y la competitividad de un país. Este es un ámbito de investigación que está evolucionado rápidamente y existen todavía muchas pistas e ideas de trabajos por desarrollar. Cada día tenemos acceso a nuevas y más detalladas fuentes de información, ya sea para el comercio, para las MNA, o para los tiempos de ejecución; permitiendo, de esta manera, seguir abriendo puertas a nuevos trabajos de investigación.

Tomando como referencia la encuesta de medidas no arancelarias que se realizó en Ecuador en 2015, ¿cuál es el diagnóstico situacional general de las empresas exportadoras ecuatorianas?

La encuesta realizada en Ecuador muestra que uno de cada cinco exportadores ecuatorianos reporta enfrentarse -con respecto a las MNA- a una situación engorrosa o difícil. Esta es una incidencia relativamente baja en comparación con otros países de la región y el mundo. Sin embargo, deja atrás algunas tareas pendientes para seguir mejorando la implementación de las MNA en Ecuador. Muchos de los casos reportados hacen referencia a MNA aplicadas por los países de destino y que, para hacerles frente, una parte del trámite se encuentra localizado en Ecuador. Esta es una situación ideal para el Ecuador, ya que le permite mejorar su competitividad de manera unilateral -sin negociaciones ni reconocimientos-, es decir, simplemente, mediante acciones propias como país y agencias nacionales que están a cargo de la ejecución de estas normas. Los desafíos más importantes están ligados a las evaluaciones de la conformidad, los certificados de origen y otros procedimientos a ser considerados durante el despacho aduanero. 
Pensando en el trabajo que realizan organizaciones internacionales como Naciones Unidas, ¿qué tipo de acciones se promueven para ayudar a las empresas - de los distintos paises - a que enfrentan los desafios de las MNA?

El ITC y otras agencias como UNCTAD, UNIDO, WCO y WTO hacen importantes esfuerzos con el objetivo de ayudar a mejorar la capacidad productiva y exportadora de los países y sus exportadores. ITC tiene, en este sentido, un rol muy importante dentro de la Iniciativa para la Ayuda al Comercio y brinda servicios que cubren los desafíos ligados a las MNA desde distintos puntos como: calidad, certificación, comercialización, información, simplificación y facilitación del comercio. Otras agencias también apoyan a los países en temas como la facilitación del comercio o el acceso a normas específicas de acuerdo con el área de especialidad de las agencias. El objetivo de estas instituciones es seguir colaborando con los países y se espera, pensando en el futuro, que los países sigan solicitando el apoyo de estas instituciones de acuerdo a sus necesidades.

Cuando se negocian o establecen acuerdos comerciales entre dos o más países, ¿cómo se incluyen las MNA y cómo estas pueden facilitar el comercio entre los países miembros del acuerdo?

En los acuerdos comerciales existe, actualmente, una noción que trata sobre la profundidad de los acuerdos comerciales y los que incluyen cláusulas sobre MNA no se limitan únicamente a aranceles y reglas de origen por lo que tienden a ser acuerdos más completos. En muchos casos, se trabaja en el reconocimiento mutuo o equivalente de normas entre los países miembros. Aquellos acuerdos que alcanzan este nivel de negociación -y que luego pueden trabajar en nuevas normas aplicables a todos los países- tienden a crear zonas más activas de comercio en su lugar de aplicación. Un ejemplo claro es el comercio intrarregional en la Unión Europea.

¿Qué recomendaciones finales daría a las empresas ecuatorianas para poder enfrentar de la mejor forma a las MNA?

Creo que existen maneras de preparar y sobrellevar los retos que imponen las MNA a los pequeños y medianos productores. Se debe adoptar y enriquecer la cultura emprendedora que busca oportunidades concretas y sostenidas de exportación sustentadas en una amplia inteligencia comercial. 
Se debe trabajar en la asociatividad para reducir los costos de implementación de tecnologías y cambios para la innovación futura, pues el mercado internacional es tan grande que trabajar juntos, entre futuros exportadores, tan solo puede ser beneficioso para nosotros mismos. Es importante mantener un diálogo abierto y franco con el sector público, no solamente con los encargados de la promoción del comercio, sino también con todos aquellos que emiten reglamentación que se aplica al comercio. Es importante que todos tomemos conciencia que la competitividad exportadora es un proceso dinámico $\mathrm{y}$, por lo tanto, debemos, continuamente, evaluar las posibilidades para ganar eficiencia a base de mejores prácticas y la implementación de nuevas tecnologías. 